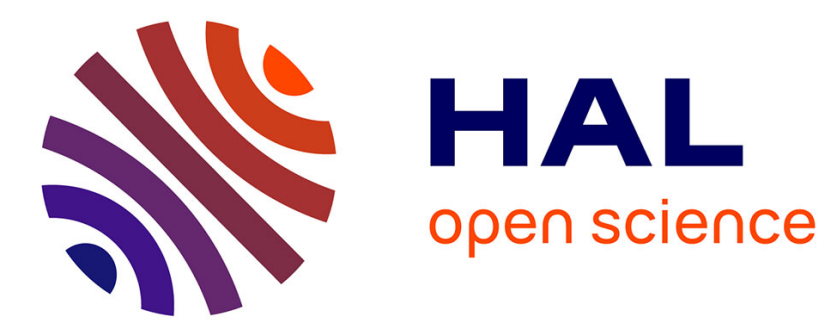

\title{
Esscirc' 85 - Conférence Européenne sur les Circuits à l'Etat Solide
}

\author{
J.P. Bailbé
}

\section{To cite this version:}

J.P. Bailbé. Esscirc' 85 - Conférence Européenne sur les Circuits à l'Etat Solide. Revue de Physique Appliquée, 1987, 22 (1), pp.1-1. 10.1051/rphysap:019870022010100 . jpa-00245509

\section{HAL Id: jpa-00245509 https://hal.science/jpa-00245509}

Submitted on 1 Jan 1987

HAL is a multi-disciplinary open access archive for the deposit and dissemination of scientific research documents, whether they are published or not. The documents may come from teaching and research institutions in France or abroad, or from public or private research centers.
L'archive ouverte pluridisciplinaire HAL, est destinée au dépôt et à la diffusion de documents scientifiques de niveau recherche, publiés ou non, émanant des établissements d'enseignement et de recherche français ou étrangers, des laboratoires publics ou privés. 


\section{ESSCIRC' 85}

\section{Conférence Européenne sur les Circuits à l'Etat Solide}

\section{Avant-propos}

La $11^{\mathrm{e}}$ Conférence Européenne sur les Circuits à l'Etat Solide s'est tenue à Toulouse du 16 au 18 septembre 1985 et a accueilli 303 participants représentant 28 nations.

Cette conférence est la réunion annuelle européenne de présentation et de discussion des derniers progrès dans le domaine des circuits intégrés. Les thèmes couverts par cette manifestation représentent un domaine clé pour la maîtrise des systèmes électroniques de demain et concernent essentiellement :

- Traitement du signal numérique :

- Techniques mixtes (analogiques-numériques).

- Mémoires.

- Conception assistée par ordinateur.

- Techniques des circuits analogiques.

Cette revue contient 4 des 8 papiers invités qui couvrent la plus grande partie des thèmes traités. Un descriptif succinct des principaux sujets discutés pendant la conférence est reproduit ci-après :

- M. VOORMAN a présenté les limitations et les difficultés rencontrées sur les filtres analogiques intégrés,

- M. ITOH a exposé les futurs développements des mémoires DRAMS et l'évolution nécessaire au niveau de leur alimentation.

- M. FREHEL a montré la possibilité de développer un formalisme unique pour la VLSI au niveau de la synthèse logique et électrique.

- M. DE MAN a reçu la récompense décernée, au meilleur papier pour sa présentation concernant les tendances de la CAO de circuits aux applications spécifiques.

J. P. BAILBÉ 